gether outside the peritoneum is that for fixing them when they have become loose. It is scarcely to be believed that only a few years ago the possibility of such a condition as floating kidney was stoutly denied, and that by men of considerable experience in abdominal work. To-day a large number of people are relieved from much suffering, and many are returned from complete invalidism to useful and comfortable life by successful nephrorrhaphy.

I have so recently fully reported my own work in renal surgery by abdominal incision, that I prefer to leave it to the judgment of the profession, and shall not, therefore, dwell upon what I believe to be the improved future, both of renal diagnosis and surgery, by the more common use of this method. I must, however, refer to one other extraperitoneal procedure which I think has been curiously neglected in the past, and which I believe will have a most useful future. I refer to Abernethy's operation for reaching the iliac vessels. I found it in a recent case, simple, free from risk in performance, and most satisfactory in the complete control it gave of the whole course of the ureter, from the kidney to the bladder, and I should not hesitate to employ it in any case of impacted calculus, or other lesion of this important tube. I think it might also be employed with advantage in place of abdominal section for the removal of some retro-peritoneal tumours.

\section{The Iliac Vessels.}

Lesions of the iliac vessels may be dealt with through the peritoneum, as well as by Abernethy's operation. Such a case of my own, which has never been fully published, I may briefly refer to as an illustration of what can be done under very unfavourable conditions. I was consulted in January, 1891, by a Norwegian, suffering from a pulsating tumour, which filled the left iliac fossa and stretched across the lower abdomen. He had some time before met with an accident, the exact nature of which I cannot recall, but I know that at the time I considered that it was the cause of his tumour, which I diagnosed as an aneurysm of the external iliac artery. It was a large pulsating swelling, was increasing, and was causing him a good deal of pain. I decided to tie the left common iliac, but could not at first make up my mind whether to do it by Abernethy's operation or through the peritoneum. He was a very short stout man, with a very fat abdomen, and not at all a nice subject for either operation, and I finally determined to employ the method with which I was most familiar, and reach the vessel through the peritoneum. The abdominal wall was enormously thickened with fat, the omentum equally so, and there was fat everywhere, and I found, when the abdomen was opened, that it was quite impossible to get any view of the seat of operation, and determined to proceed by touch alone. I first verified the diagnosis, then found that there was a short but sufficient portion of the common iliac artery uncovered between the aneurysm and the bifurcation. With a little careful manipulation I raised the peritoneum covering the sheath and divided it, introduced my finger through the opening, and noted the relations of parts, pinched up a portion of the sheath of the vessels and rolled it between my finger and thumb till I felt quite certain that I was clear of the ureter nicked the portion held between my finger and thumb with probe-pointed scissors, isolated the artery without difficulty, and tied it firmly by gentle steady pressure, but not too tightly, with a single No. 3 Chinese twist silk ligature, cut the ends short and closed the abdomen. There was never any pulsation in the aneurysm afterwards, and it rapidly diminished in size. There was no trouble with the leg, which was carefully supported and wrapped in a large quantity of -cotton wool; and he was up and well, with but little trace of the aneurysm, in about six weeks; and when last heard of was in excellent health.

Gentlemen, with the record of this somewhat unusual but, fortunately, successful bit of abdominal surgery, my too lengthy address draws to a close. When thinking over possible subjects, it occurred to me that a glance over the whole field of abdominal surgery, with some few illustrative cases, and some indication of the directions in which farther advance still seemed likely and possible, written by one who has been among the most active and enthusiastic workers in this fascinating branch of surgery for twenty-five years!; who found it, though of some age, still in its very infancy; who has helped in some measure to guide its tottering footsteps, and plant them firmly in a strong maturity, might be of interest alike to those who are my contemporaries, but whose life work has brought them only occasionally into touch with abdominal surgery, and to those who come as a younger generation to inherit a fine and improved estate, but one that I have endeavoured to show will well repay them for future labour. If I have not wearied too many of you, have interested some, and, above all, have suggested useful thoughts to those who hope to do useful work, I have attained my end.

\section{THE MILROY LECTURES ON}

\section{THE VALUE OF ISOLATION AND ITS DIFFICULTIES.}

\section{Delivered before the Royal College of Physicians of London.}

By EDWARD SEATON, M.D., F.R.C.P.,

Medical Officer of Health to the Administrative County of Surrey: Lecturer on Public Health, St. Thomas's Hospital.

LECTURE I.

AFTER some introductory remarks the lecturer said he had chosen as his subject a department of the health officer's work in which some progress had been made since 1872, and in which far more would have been accomplished if only medical knowledge in matters relating to the public health had been duly appreciated and acted upon.

After referring to Sir John Simon's account of "isolation" and quarantine as carried out in former days in the case of such diseases as leprosy, the Black Death and the plague, Dr. Seaton proceeded:

The Cruelty of Quarantine.

The spirit which prompted and still prompts these quasimilitary precautions, which have lasted through so many centuries even to the present day, was and is in reality, though not intentionally, exceedingly cruel. We need not search the pages of history to demonstrate this. The story of the cholera in Spain only a few years ago shows plainly enough how, under the influence of panic, the old spirit may at any time be revived, and be as cruel in its manifestations as it ever was in the Middle Ages. Nothing but the steady education of public authorities by responsible advisers or officers in medical as well as in other matters will ever dispel it. It prevailed in England even in the time of the famous Dr. Richard Mead, physician to St. Thomas's Hospital. Indeed, in his celebrated Discourse concerning Pestilential Contagion and the Methods used to Prevent it, Mead starts with 'the assumption that "quarantine" as carried on then and even now in parts of Europe was essential. How different a spirit is now in the ascendant is evidenced in a number of ways. Here let me distinctly say that by "quarantine" is meant the unscientific and consequently useless restrictions generally denoted by that name-restrictions which are even to the present day insisted on by the otherwise enlightened Governments of some European countries.

Coast Isolation.

I would emphasise and dwell upon this point because ou system of medical inspection combined with "coast isolation," if I may so term it, in distinction to "quarantine," is at the present day insisted upon as a very essential part of our defences against invasion by certain epidemic diseases. Within the last few weeks the Local Government Board has issued a volume full of interesting details and important information on the subject of our defences against cholera. The necessity for isolation hospitals along our coast line at the port sanitary districts in communication with foreign countries for the reception of persons actually suffering from cholera and other infectious diseases brought to these shores is not only ad mitted but insisted upon.

[The lecturer here quoted passages from the Port and Riparian Sanitary Survey of England and Tialıs, $1893^{-4}$, in 
which the condition of our general port sanitary administration is described, showing that when the port survey was commenced it was found that in only one-third out of a total of sixty port sanitary districts could the general administration be regarded as satisfactory and efficient. He proceeded :]

Not only does this volume of " reports and papers" contain a vast amount of important information from the point of view of practical administration, but it also incidentally affords striking proof of the value of the survey itself, carried out as it was when this country was threatened with cholera invasion. The actual additions to our permanent defences against importation of infectious diseases generally provided at the expense of the various local sanitary district authorities, either whilst the survey was in progress or since its completion, shows that up to the end of 1895 they form a considerable part of the whole of our system (some material or substantial improvement having been made in 44 out of 60 cases). I would specially emphasise the statement that as regards "coast isolation" and the correlated measures of administration this provision is essentially necessary for other purposes besides cholera.

From a study of the writings of my distinguished and learned colleague, Dr. Payne, I gather that in the case of plague similar isolation precautions would be necessary, taking into account, of course, the essentially different ways by which the two diseases, cholera and Oriental plague, are spread. Dr. Payne, in editing the account of the Great Plague of London in the year 1665 , by William Boghurst, gives an impartial summing up of the contagionist and localist explanations of the plague. In favour of Hirsch's view he says there are the facts that the disease came originally from the East, that a general succession of epidemics from east to west was often observed, and that its recession in the seventeenth and eighteenth centuries followed inversely the same law. In England, for instance, epidemics were often preceded by outbreaks in Holland. "In England, too, the incidence of the disease in seaport towns was far more severe than in those inland ; and it is extraordinary how much more frequently and severely the east of England, which was in communication with the Continent, was affected than the west." He adds, "The infection of Yarmouth before London in the autumn of 1664 is a striking fact." So that it would appear that, as in the case of cholera, so in that of Oriental plague and yellow fever a coast isolation system is required in this country. The last-named disease, yellow fever, was brought to our shores at Swansea in september, 1865. It was in connection with this outbreak, and also in relation to the concurrent prevalence of cerebro-spinal meningitis in epidemic form in places about the Lower Vistula, that, as it will be remembered, formal official declaration was made on the subject of contagion in its public health aspects and on "Quarantine." "So also it may be in the case of typhus fever, with regard to which I learned some interesting facts at New York in 1887. Within the last few weeks I have received a letter from Dr. J. S. Billings, expressing strong opinions upon the value of isolation in the case of this disease, as exemplified by the experiences of New York City. In Australia and in the Colonies also I have gathered from the verbal communications of those who know the facts, that in the case of small-pox, coast isolation has certainly been of great value.

Again, in our own country, small-pox and fevers need to be isolated when brought into our ports, whether by "coastwise" or "foreign" traffic. So that briefly stated, that part of quarantine which consists in intelligent isolation, kindly and thoughtfully carried out, is and must as a matter of course be part of a well-organised sanitary system in any country.

Mead's "Cautions."

The celebrated Discourse by Dr. Mead, to which I referred at the outset of this lecture, comprises two "cautions." The first relates to "the prevention of disease being brought into our island," that is to say to quarantine. "Near to our several ports there should be lazzarettos built in convenient places on little, islands, if it can so be, for the reception of both men and goods which arrive from places suspected of ${ }^{1}$ Vide Public Health Reports, by John Simon, edited by Edward Seaton. infection." This is a subject that I need not dwell upon further, seeing that quarantine in this sense has been abandoned for England.

The second "caution" relates to "the putting a stop to the disease spreading amongst us" when imported. This is more immediately interesting to us at the present day, when by increased facilities of travel it has become impossible to keep out those of the infectious diseases which have long periods of incubation, even when cases are imported from distant parts of Europe and even other quarters of the globe. Furthermore, the teaching and work of at least two generations of men have been devoted strenuously and earnestly to the task of improving the conditions under which the people are housed, and preventing the recurrence of nuisances injurious to health; so that it seems we can afford to let certain kinds of infectious disease be imported into. our midst, if not with impunity, at any rate with infinitely less danger than in former days.

It was in view of the possibility of the reinfection of England from a "miscarriage in the public care" that Mead gave his second "caution." Let anyone study this part of the Discourse by the light which experience affords in dealing with the problems of infectious diseases and their methods of prevention, and he cannot fail to perceive that the practice which we have been endeavouring with much labour and in spite of many difficulties to establish during the last quarter of the present century is identical with that which is so forcibly indicated by this wise physician of the early part of the eighteenth century. Indeed, the principles laid down by Dr. Mead in 1720 are precisely those which I believe this College would not only approve but desire to see enforced as far as possible by those who hold the responsiblepositions of medical officers of health. Is not, then, he who. by precept did so much to create a better understanding of the spirit in which the dangers of pestilence ought to be met rightly named first among the fathers of modern preventive medicine?

\section{Meaning of Isolation.}

But before proceeding to discuss these principles. and their application in practice, let me take the opportunity of saying a few words on the use of the term "isolation" (in modern preventive medicine) which is obviously open to criticism. Surely there would seem to be something like a contradiction in terms in calling what frequently amounts to a " massing together" of a number of persons, isolation. As used in the language of medical science, this word implies the treatment of persons apart from the general population. This is different from the meaning of the term when used as in ordinary language, where it denotes individual seclusion. The imprisonment of the unfortunate occupant or occupants of dwellings infected with the plague in the Stuart period might be spoken of as isolation in the latter sense. At that time, we are told, by the orders of the Lord Mayor of London, published in 1665 , houses were kept "shut up, with a large red cross and 'Lord have mercy upon us' on the door, and watchmen to attend day and night to prevent anyone except physicians, surgeons, nurses, watchers, etc., going in or out; and this to continue a month after everyone was dead or recovered." Such treatment, cruel in the extreme, does obviously constitute isolation in one sense; but it is equivalent to quarantine! Nothing of the kind is intended by the word as used here. Isolation carried to such an extent would of course never be thought of at the present day. It would, in fact, speaking generally be regarded as a public danger. It is interesting, however, to observe that under the influence of the panic which a disease such as small-pox is able to create in populations where vaccination is coming to be systematic ally disregarded, something which looks like a revival of the obsolete system seems to be for a time possible. A most valuable report, printed by order of the Sanitary Committee of the Borough of Leicester, and prepared by Dr. Joseph Priestley, who was Medical Officer of Health for that town during the small-pox epidemic of $1892-3$ (a report to which $\mathbf{I}$ shall have occasion to refer later), shows that an amount of surveillance, domestic intrusion, and interference with personal liberty can be submitted to, even in an English town at the present day, which bears some resemblance to the system which was possible at the time of the plague. 
[The "Small-pox Quarantine Rigulations" as given in Dr. Priestley's Report were here quoted.]

The term "isolation," so far as I intend to use it in connection with English precautions, applies to the taking of dangerously infective cases " out of " the centres of population-whether it be to ships, as on parts of our coast, and on the River Thames, as at Long Reach; or to islands, as is done at New York; or to convalescent homes, as at Winchmore Hill ; or to any favourably situated site in the open country mear to a large manufacturing town, as at Bagthorpe, near Nottingham. Any one of these plans would be regarded as isolation in the sense of modern preventive medicine; for, under such circumstances, every hygienic advantage is secured to the sufferers, as well as to the public, although, so far as the sufferers are concerned, company rather than solitude is frequently implied.

Mead introduces his second caution by saying that there is " no evil in the world in which the great rule of resisting the beginning more properly takes place than in the present case" (he is dealing with the plague), "and yet it has unfortunately happened that the common steps formerly taken have had a direct tendency to hinder the putting this maxim in practice." For not only did the "shutting of all houses" prove ineffectual as a means of staying the development and spread of contagion, but the cruelty which this system involved or necessitated led to that which has always been the bane of preventive medicine, namely, the concealment- often the organised concealment-of dangerously infective disease.

Care of the Sick the First Principle of Isolation.

The first great principle, therefore, to be insisted on is that all preventive work should be carried out in the spirit of tender care for the sick persons and their friends. To quote Mead's words: "No manner of compassion and care should be wanting to the diseased, to whom, being now in clean and airy habitations, there would be with due cautions no great danger of giving attendance; all expenses should be paid by the public, and no charges ought to be thought great which are counterbalanced by the saving of a nation from the greatest of calamities."

Can we be said to have entirely succeeded in giving effect to this advice, even at the present day? Undoubtedly great improvement has taken place in our methods of dealing with the beginnings of outbreaks or epidemics. During the twenty years or more which have elapsed since the Public Health Act became law, great advance has been made in the formation of public opinion, by which alone a sound basis of administrative action can be secured. Yet there are still manifestations that under the influence of panic a line of action may be adopted by local authorities, which savours rather of persecution. I have already referred to what has happened in a midland town. In another city, north of the Tweed, legislative proposals were drafted some fourteen years ago to enable the representative of the local sanitary authorities forcibly to make examinations for purposes of diagnosis by the authority of a local Act of Parliament. This innovation not unnaturally provoked the opposition of those who make the preservation of personal liberties their special care. The appointment of a Special Committee of the House of Commons to watch Sanitary and Police Bills followed as a matter of course. We may with satisfaction refer to the firm stand taken by our Government Medical Department on the vital question of abolishing quarantine, with its apparently useless and frequently cruel restrictions. This ought to make us all the more careful not to sanction procedures by municipal corporations, which are obviously cruel, even when they are adopted on grounds which seem plausible enough to enthusiastic representatives of local self-government.

The spirit in which preventive medical work is carried on is of fundamental importance, for if it be not well understood beforehand that proper consideration will be given to the unfortunate sufferers and their friends, how can it reasonably be expected that the initial difficulties attending the prevention of epidemics by means of isolation would ever be overcome? The precautionary measure of primary importance is the cultivation of the art of diagnosis. In Mead's time "ignorant old women were generally appointed searchers in parishes to inquire what diseases people die of." There was at that time, of course, no proper recognition of the functions of educated and skilled physicians by the State. By slow degrees those functions have come to be more and more recognised. But even at the present day we are far from having attained to what might be considered practicable from the administrative point of view. Skilled medical knowledge has been held too cheap in this as in other matters affecting the public interests, and as a result much preventable illness prevails.

The Importance of Accurate Diagnosis.

It would be easy. to show, were it necessary to do so, how even the most intelligent of the general public fail to understand the value of diagnosis, whether as regards the acquirement of the art or the serious consequences that may follow a mistaken diagnosis. Within the last few weeks a note of warning has been sounded in a special article in the Times on infectious diseases in London. The absolute freedom from typhus fever of the vast population of the metropolis since the early part of 1887 , when small outbreaks occurred in different parts of London, is a subject of congratulation, and bears silent testimony to the value of past labours of many active sanitary authorities and energetic officers. At the same time, under the authority of Mr. Shirley Murphy, President of the Epidemiological Society, Londoners, and indeed the inhabitants of all large towns, are warned of the danger that may possibly arise from this very absence of opportunity for studying and teaching distinguishing features of typhus. The want of opportunity in this case arises from the entire absence of the disease, but in the case of scarlet fever, measles, rötheln and influenza, chicken-pox and smallpox, we have examples of diseases which are domiciled amongst us, and the diagnosis of which, regarded from the public point of view, may at any moment be important.

Mead advises that the office of diagnostician should " be committed to understanding and intelligent men," whose business should be to give notice of the existence of what was believed to be dangerous infective disease to magistrates, who should immediately call in skilful physicians to report. Then if upon their report it appeared that the pestilential distemper had broken outamong the inhabitants, they. should without delay "order all the families in which the sickness is, to be removed; the sick to different places from thesound; but the houses of both should be three or four miles out of the town." The removal of the "sound" (that is persons not actually ill, but who have lived in the infected dwelling) may be regarded as a "counsel of perfection" impossible of attainment under any conditions; but the first recommendation proves to be of the greatest practical utility. So that immediately a diagnosis is arrived at and confirmed, measures are to be taken for the public safety, and there are consequences very materially affecting the victims of the attack. It is plain, then, that accuracy of diagnosis is the first, and therefore the most valuable, of all measures of prevention, and that it constitutes the basis of our whole system of defence. How much more we are coming to recognise its importance has been shown by the action of our College in obtaining through the Local Government Board in I889 increased facilities for the clinical study of the endemic infectious diseases, and further, by the opportunities given by our College, along with its sister College and other public bodies, for improved methods of diagnosis by means of bacteriology. On these important topics I shall have to speak later, but, before concluding this part of my lecture, I must refer to another great principle laid down by Mead, at the conclusion of the sentences above quoted. In advocating the removal of the sick, he says "that the houses of both [meaning the occupants of infected houses, sick and sound] should be three or four miles out of the town;" in other words, the isolation should be true isolation, and not that which is often made to pass muster as hospital isolation, even at the present day. As a considerable part of my next lecture must necessarily be devoted to certain aspects of the extremely interesting problem of preventing small-pox, I must insist on the importance of Mead's postulate, namely, that. infectious diseases should be isolated outside towns.

Infectious Diseases Twenty-five Years Ago.

I have hitherto confined myself mainly to a discussion of 
principles which may be said to have been laid down for our guidance nearly two centuries ago. I would now ask you to let me give a brief review of the prevailing conditions under which infectious diseases were treated early in the "seventies," at which time several of us, as officers of health, became officially responsible for their prevention and treatment. At that time the prevailing diseases of the zymotic class of which sanitary authorities had to take account were the same as now, except that typhus fever, although still existing, was gradually diminishing in London, Liverpool, and other great towns. Relapsing fever, which assumed epidemic proportions in 1869, had disappeared in 1870 . Consequently the diseases generally prevailing at that time which may be said to come within the scope of the sanitary authorities were the same as now, namely, typhus (already becoming rare), smallpox, scarlet fever, typhoid fever, and diphtheria. Measles and whooping-cough, though accounting for a considerable share of mortality then as now, had not been, and indeed have never been, brought within the scope of measures of sanitary precaution, except so far as these concern sickness of all kinds. The maintenance of these two diseases at the same level in spite of sanitary improvements shows that we do not yet understand the method of their prevention. Typhus was fast diminishing under the influence of sanitation. The better conditions of housing and living, which in former generations had proved so powerful in depriving plagues of their virulence, were gradually bringing about the same result in the case of this disease. Small-pox was apparently uninfluenced then, as it appears to be now, by such measures, and in spite of our systematic vaccination of infants it was about to inflict a death-rate on the population (that is, the unvaccinated and the adult unrevaccinated population) which for the first time for many years formed an appreciable part of the annual returns. Scarlet fever still prevailed in a virulent form. Whether the attack-rate of the disease was, comparing it with that now prevailing, much greater, it is obviously impossible to determine with certainty, inasmuch as nowhere at that time was there any reliable system of notification or registration of diseases. [Reference was here made to the milder character of this disease of late years.]

Typhoid fever was coming to be regarded by experts in the light of an entirely preventable disease, owing chiefly to the forcible demonstration and teaching of the medical department of the Local Government Board, whose observations on this subject were summed up in Simon's essay on Filth Diseases. In the case of this disease, as in that of Asiatic cholera, isolation was considered then, as it is indeed now to be of secondary importance. The chief protection against these diseases was believed to be the safeguarding of water supplies, the prevention of food infection, etc.

Diphtheria-for what reason we cannot explain-had somehow come to be accounted a "filth disease" like typhoid, and for several years the action taken by sanitary authorities was based on the assumption that this disease was also amenable to measures of cleanliness, and that its very existence was an indication of some gross neglect on the part of the sanitary authorities or individuals. The evidence on which this assumption was founded escaped criticism, and eonsequently scientific inquiry and observation gave place to so-called "practical" measures. But, however strong the evidence was with regard to both typhus and typhoid, and their dependence upon what was then somewhat narrowly called "sanitary conditions," the evidence connecting diphtheria with such conditions has been of a very different character.

Hospitals for Infectious Diseases.

Hospitals for infectious diseases in England dated from nearly a century before 1872 . At that time they had begun to supersede the old parish pesthouse, which had till then formed the only special provision for the treatment of the infectious sick. The original design of these hospitals was to promote the recovery of the individual poor patient, for whom accommodation was necessary; indeed, the name "house of recovery" was a frequent synonym for infectious diseases hospital at the period when the necessity of such an institution was first recognised. But it followed as a matter of course that the advantages to be obtained by the district possessing a hospital soon became evident, and from a very early period of their history infectious diseases hospitals have been advocated on the ground of their protecting the household, and consequently the public, against the spread of infection. About the time of which I am speaking there were, however, only two special infectious hospitals in the metropolis, and hardly any of the large towns had any means at all of isolating fevers or small-pox in separate buildings, either within or without the precincts of the town. In London there was the old Small-pox and Vaccination Hospital, which had been removed to Highgate, where it now is, and the Fever Hospital (now used for private cases) in the Liverpool Road, Islihgton. Both these hospitals were supported by voluntary contributions, and they were in no sense municipal institutions. The former received severe cases of smallpox, and the latter severe cases of typhus, enteric, and scarlet fever. These diseases were also received into. the airy and spacious wards of the general hospitals. But the great majority of the cases, especially those of a mild character, which were recognised to be important from the public health point of view, were treated at their homes. A large part of the practice of the dispensaries supported by voluntary contributions consisted in attending the infectious sick. Besides these, amongst the classes above those who obtained entirely gratuitous medical relief were vast numbers who, if infectious disease occurred in their households, were quite unable to isolate it efficiently at home, or to procure suitable means of isolation elsewhere. At that time infectious fevers amongst the poor and amongst the independent wage-earning classes may be said to have run their course almost unchecked so far as effectual isolation is capable of controlling them.

Institution of the Metropolitan Asylums Board.

It was then that the Asylums Board was constituted under the Metropolitan Poor Act of 1867. Its purpose was to estäblish in the metropolis asylums for the sick, insane, and other classes of the poor. The name of the Act as well as the use of the term "asylums" indicates the intention of the Legislature at the time. It was in accordance with the view already expressed as to the raison d'être of a hospital. It was mainly to relieve the workhouses of the infectious sick and the insane that these asylums were required. As far as infectious diseases were concerned, there seems to have been no wider intention in their establishment than that of providing separate means of isolation for cases which could not be effectually isolated within the workhouse walls. The constitution of the Board was, as it is now, almost entirely representative of Poor Law authorities. Thus there was created for London a Board which was destined to have important sanitary functions; but which was not representative of the sanitary authorities. The vestries, which in all other respects were the sanitary authorities, have at various times been criticised for not having taken independent action for the provision of hospitals, but few who have studied the question, and have had practical experience of the difficulties of hospital provision and administration, or who are acquainted with the boundaries of London parishes and the intricacies arising therefrom, can doubt that this work at any rate was far better in the hands of a central authority, whether such central authority is representative of the Poor-law or of public health administration in a large sense.

Small-pox Hospitals.

To complete this brief review of the state of affairs about a quarter of a century ago, I must now refer to what was found in the seventeen large towns of England, of which the Registrar-General at that time gave weekly statistics. The population of these towns in the aggregate amounted to something like three millions, about equal to that of the metropolis as a whole. The great pandemic wave of smallpox, which spread over England in 1871-72, had proved that our vaccination system alone, although absolutely protective of the young, was insufficient to protect the population as a whole against what might be termed epidemic diffusion of the disease, by which I mean such an extension of the disease as would appreciably affect the general death-rate of these seventeen large towns for as long a period as a year, just as they were affected by the influenza 
epidemics of $1892-3$, and by measles epidemics at various times. Not only the absence of systematic revaccination, but the absence even of facilities for carrying it out, afforded by our then existing system of public health administration, made the want of isolation specially conspicuous (although it may be doubted whether revaccination, unless thoroughly systematic or in a sense compulsory, would have been entirely successful). The fact that the adult population suffered largely under the visitation (which as measured by its effect on the death-rates was severely felt, like the influenza epidemic of recent date), together with the horror of the disease and the interference with trade which it involved, greatly added to the panic and the loss of property that followed. The way in which the disease was seen to spread by the sometimes unavoidable and sometimes careless exposure of infected persons and things at public-houses, laundries, provision shops, etc., as well as in the workhouses and common lodging-houses, forced attention to the question of isolation. This had hitherto been kept in the background by the habit of relying wholly on vaccination as the great preventive measure against small-pox. Under the influence of panic small-pox hospitals so-called were erected, but this did not take place anywhere until the disease had got firm hold of the population, and consequently they were of little or no use in preventing epidemic diffusion.

It often happened that with small-pox-that most infectious or contagious of diseases - such accommodation had to be provided on some open space well within the precincts of the town, and which could not be regarded, therefore, as true isolation. Mead's view, so far as it relates to the sufferers being removed a distance of three or four miles out of the town, was perhaps more practicable when the whole population of the country was much less and when towns were very much smaller in size.

The policy, indeed, of dealing with so highly contagious a disease as small-pox by the segregation of large numbers of cases within the precincts of any large town had from the beginning been regarded with distrust and suspicion by eminent and experienced Fellows of this College, some of whom gave their opinions in evidence at a well-known trial in the law courts about five-and-twenty years ago. Later, Dr. Bridges, the Local Government Board adviser on medical Poor-law matters of the metropolis, and others whose experience was of the highest value, gave evidence also before a Select Committee of the House of Commons on the Hampstead Fever and Small-pox Hospital in 1875. How far this distrust and suspicion were found to be justified by subsequent events belongs to the history of the following decade. I will, therefore, conclude this lecture, which deals mainly with the subject of the beginnings of isolation regarded from the modern point of view.

\section{THE PHYSIOLOGY OF THE CARBOHYDRATES.}

A Rejoinder to Dr. Paton's Further Criticism.

BY F. W. PAVY, M.D., LL.D., F.R.S., Consulting Physician to Guy's Hospital.

(Continued from page 455.)

I HAVE said that Schenck himself acknowledged that his work was unsound. He performed fresh experiments by a process differing from that employed by him before, and obtained results of a nature directly contradictory to those set out in his previous paper. At the suggestion of Professor Pflüger he conducted also some dialysis experiments, and found ${ }^{1}$ that the added sugar dialysed from the blood. Finally he sums up in a paragraph, of which the following is a translation : ${ }^{2}$

It follows from these experiments taken as a whole that the sugar in blood and serum is in free solution. The experiments also tell against my conjecture that the explanation of the loss of sugar in the analyses published previously is to be sought in a combination between the suga of sugar in the coagulum is to be accounted for by mechanical circum-

It is such work as this which Dr. Paton reproves me for ignoring, saying that "coming as it does from Professor

$$
\begin{aligned}
& 1 \text { Pfliig. Arch., xlvii. } \\
& 2 \text { Loc. cit., p. } 627 \text {. }
\end{aligned}
$$

Pflüger's laboratory in Bonn it must be received with respect, and cannot simply be ignored," and that "it has a most important bearing on all I)r. Pavy's work, and is worthy of his careful study and consideration."

Dr. Paton imputes to me contempt for the work of others. I do not admit the justice of this allegation; but I admit frankly that it has been my principle of action through . life never to found conclusions upon statements the accuracy of which I had not tested for myself by personal experiment. Dr. Paton, on the other hand, judging from the course of action he has pursued in his criticism of my work, deems it right to seize upon anything which may seem likely to serve his immediate purpose without stopping to consider the question of its validity. Does not his use of Schenck's earlier paper in the manner which I have here explained afford striking support for the remark made in my Epicriticism that "anything seemingly that has come to hand that could be applied to disparagement has been eagerly grasped at"?

Let me proceed a step further and invite attention to the nature of the proposition which is made. It is nothing less than that glucose, on being simply added to blood, straightway enters into combination with the albumins present. The words employed in the passage quoted by Dr. Paton from Schenck are: "It is highly probable from this that the glucose is combined with the albumins of the blood." That such a proposition should be brought forward without the slightest pains being taken to examine into its soundness must surely impress everyone as an extraordinary method of procedure. Relying as he has done for his criticism upon published literature, and so well versed as he appears to be in it, is it not surprising that he should be unacquainted with Schenck's own contradiction published in the succeeding volume of Pfüger's Archiv; of Röhmann's and of Seegen's attacks upon the first article in the Centralblatt für Physiologie, vol. iv, 1890 ; and of Dr. Vaughan Harley's experimental and critical article in the Journal of Physiology, 1891 ?

But Schenck's earlier paper is made to do still further duty by Dr. Paton in his observations on the glucoside constitution of proteid matter. In his original criticism ${ }^{3}$ Dr. Paton, in referring to the osazone which I had obtained from the sugar. derived from proteid matter, remarked: "It is only when an elementary analysis of the compound is made that it can be definitely concluded that a carbohydrate is a constituent part...... but Dr. Pavy does not give such analyses, and without them we are not justified in accepting his conclusion that the substance is a carbohydrate."

In my Epicriticism (p. 25 et seq.) I supplied an elementary analysis showing that the body was beyond doubt a sugar osazone. Dr. Paton now renews his attack upon another line, which, be it remarked, is suggested $\mathrm{by}$-if, indeed, it may not be said to rest entirely on-Schenck's work, the unsoundness of which I have fully exposed. Dr. Paton writes : But the question still remains: Was the albumin from which osazones
were prepared by Dr. Pavy free of carbohydrate bodies in mere were prepared by Dr. Pavy free of carbohydrate bodies in mere an integral part of the molecule? Sclienck's results, already considered, show that pixtures of carbohydrates with albuminous substances are formed, which may account for Dr. Pavy's results. But Dr. Pavy refuses formed, which may account for

to consider these observations. As I said before, I do not deny that a carbohydrate may be yielded by the splitting of the proteid-the albuminous-molecule; but I did say, and still maintain, that all Dr. Pavy has yet proved is that, in the solution of proteids by caustic potash or sulphuric acid, a carbohydrate substance convertible into sugar is set free, which was either loosely combined with the proteid or formed an integral part of its molecule. Until the work of Schenck has been satisfactorily dealt, with an open
mind must be kept on the subject. Undoubtedly the fact that an mincreased amount of reducing substance is obtained by the use of stronger increased amount of reducing subst

Looking at the position in which Schenck's work, relied upon here by Dr. Paton, has been shown to stand, what need be said in reply to this criticism? "Until," says Dr. Paton, "the work of Schenck has been satisfactorily dealt with, an open mind must be kept on the subject." It is alleged that the carbo-hydrate may have come from carbohydrate incidentally, as it were, present. " Schenck's results, already considered, show that mixtures of carbohydrates and albuminous substances are formed, which may account for Dr. Pavy's results. But Dr. Pavy refuses to consider these observations." I do not know whether Dr. Paton will still 